\title{
20160 ano dos megaeventos esportivos e das grandes incertezas
}

2016 the year of mega-sport events and the great uncertainties

2016 el año de mega eventos deportivos y de gran incertidumbre http://dx.doi.org/10.18472/cvt.16n3.2016.1344

Roberto Bartholo〈bartholo@pep.ufrj.br >

Editor chefe do Caderno Virtual de Turismo. Professor do Programa de Engenharia de Produção da COPPE da Universidade Federal do Rio de Janeiro (UFRJ), Rio de Janeiro, RJ, Brasil.

Ivan Bursztyn 〈ivan@gastronomia.ufrj.br >

Editor científico do Caderno Virtual de Turismo. Professor do curso de gastronomia da Universidade Federal do Rio de Janeiro (UFRJ), Rio de Janeiro, RJ, Brasil.

Aguinaldo Cesar Fratucci 〈acfratucci@gmail.com >

Editor científico do Caderno Virtual de Turismo. Professor do Programa de pós-graduação em Turismo da Universidade Federal Fluminense (UFF), Niterói, RJ, Brasil.

Luis Tadeu Assad 〈assadmar@iabs.org.br >

Editor científico do Caderno Virtual de Turismo. Diretor presidente do Instituto Brasileiro de Desenvolvimento e Sustentabilidade (IABS), Brasília, DF, Brasil.

FORMATO PARA CITAÇÃO DESTE ARTIGO

BARTHOLO, R.; BURSZTYN, I.; FRATUCCI, A.C.; ASSAD, L.T. 2016 o ano dos megaeventos esportivos e das grandes incertezas. Caderno Virtual de Turismo. Rio de Janeiro, v. 16, n. 3, p.68, dez. 2016.

REALIZAÇÃO

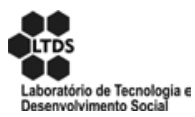

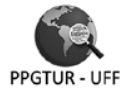

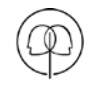

IABS
APOIO INSTITUCIONAL

COPPE

UFR]

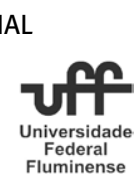

EDIÇÃO

PATROCÍNIO

IPQTOR
(2) FAPER. 
O ano de 2016 está terminando e, certamente entrará para a história do turismo brasileiro como o ano dos megaeventos esportivos sediados na cidade do Rio de Janeiro. Paralelo ao momento atual denso, intenso e turbulento das nossas condições políticas, sociais e econômicas, o turismo brasileiro manteve-se ativo e, diretamente influenciou e foi influenciado pela realização dos Jogos Olímpicos e Jogos Paralímpicos, nos meses de agosto e setembro.

Nesse contexto, a cidade do Rio de Janeiro, principal destino turístico brasileiro, foi território de grandes transformações urbanas que culminaram com o desvelamento de novos cantos, recantos e paisagens, quase que esquecidas e escondidas do carioca. Processos de reestruturação urbana, de refuncionalização de diversos fixos, de reorientação de fluxos e também, de gentrificação em algumas das áreas atingidas pelos primeiros, foram desenvolvidos pelos grupos gestores da cidade, nem sempre de maneira participativa. Muito do passado da cidade do Rio de Janeiro ganhou a oportunidade de se "revelar": o cais do Valongo, a área da pequena África, a praça da Harmonia, o morro da Conceição ficaram mais acessíveis e instigam e estimular a todos a caminhar pelos seus caminhos prenhes de histórias, estórias e, por que não, de lendas. Um novo espaço foi (re)construído na zona portuária da cidade e criou uma nova área turística que, imediatamente foi apropriada pelos moradores, pelos visitantes e pelo mercado turístico nacional e internacional...

Ruas, avenidas e becos, antes vazios nos finais de semana e depois do entardecer agora se mostram plenos de vida, de movimento e de pessoas ávidas por descobri-los e vive-los. Resta saber se e como todo esse movimento se manterá na linha do tempo. Qual será seu horizonte temporal sustentável? Finda a curiosidade, os moradores, os visitantes e o mercado manterão seu interesse pelo agora famoso Bulevar Olímpico? E as visitas guiadas pela área do Cais do Valongo, dos Jardins Suspensos do Valongo, do Largo da Prainha, da Pedra do Sal continuarão depois do próximo verão? O interesse pelo Museu do Amanhã, imenso exemplar pós-moderno ficando no píer até então abandonado da Praça Mauá, e o Museu de Artes do Rio de Janeiro -Mar, terá a mesma intensidade no próximo ano:

Questões que ainda não têm respostas, mas que precisam ser estudadas e respondidas. Tudo ainda está à espera de estudos e pesquisas e, principalmente, de resposta para aquela questão que paira ainda no ar: quem ganhou e quem perdeu com todo esse movimento?

Novo ano, nova administração municipal, cenário econômico e político mais que conturbado, fazem do nosso futuro próximo um momento de grandes incertezas.

Dando continuidade ao cumprimento de nossa principal missão de divulgação eletrônica de artigos originais e resenhas críticas de estudos voltados para o debate do turismo como vetor de desenvolvimento social, o presente número do Caderno Virtual de Turismo traz doze artigos inéditos e uma entrevista com o professor Conrad Lashey daStenden University of Applied Science da Holanda, além de uma resenha do seu novo livro, The Routledge Handbook of Hospitality Studies, lançado recentemente sobre o tema da hospitalidade, com estudos de casos de todos os cantos do planeta.

Nos artigos ora publicados temos a oportunidade de navegar por áreas temáticas distintas, mas que se tangenciam ora do ponto de vista metodológicos, ora do ponto de vista de suas construções teóricas. O Turismo de Base Comunitária volta a compor o conjunto do Caderno, com mais quatro pesquisas que se alternam em apresentar metodologias de planejamento participativo e questionamento entre as reflexões teórico-conceituais e a realidade empírica de localidades que aderiram a essa modalidade de desenvolvimento turístico.

A presença de dois artigos internacionais trazendo discussões sobre o turismo em Portugal e no México, contribuem para o esforço de internacionalização do Caderno Virtual de Turismo e nos brindam 
com estudos específicos, porém, atuais e instigantes. Do México temos um estudo sobre a avaliação dos recursos turísticos naturais do município de San Pedro Lagunilhas, no estado de Nayarit, na costa ocidental daquele país, a partir de metodologia de avaliação multicritérios (EMC). $\mathrm{O}$ artigo dos pesquisadores da Universidades de Vigo e Extremadura, na Espanha, por sua vez, nos levam a refletir sobre um dos muitos caminhos de peregrinação para San Thiago de Compostela. A partir de pesquisa de campo, os autores nos apresentam as potencialidades do trecho do Caminho no município de Vila Nova de Gaia, Portugal, indicando algumas necessidades de intervenção para tornar a experiência do peregrino-turista mais confortável e complexa.

A questão da experiência e do comportamento permeiam dois artigos que se voltam para o estudo do comportamento e das características socioculturais dos turistas e visitantes de dois segmentos bastante específicos e ainda pouco estudados pela academia: os turistas de mergulho e os mochileiros no Brasil.

Outra questão atual e pertinente que pode ser observada em dois artigos que tratam de objetos empíricos distintos, porém, com pontos de contato, é a da influência dos desastres naturais nos processos de planejamento e reestruturação de destinos turísticos. A região da Costa Verde e Mar de Santa Catarina e o município paulista de São Luiz do Paraitinga são o foco desses estudos que se tangenciam por analisar os efeitos de desastres naturais recentes sobre suas atividades turísticas.

Esse universo de investigação amplo e instigante é complementado pela entrevista com o professor Conrad Lashley, realizada pelo pesquisador Leandro Brusadin, da Universidade Federal de Ouro Preto, nos leva a refletir sobre o sentido do acolhimento nos estudos da hospitalidade. Salientando a urgência das nossas universidades estimularem o desenvolvimento do pensamento crítico nos alunos, professor Lashley nos indica que educar "não é só preparar as pessoas para a indústria, é educá-las como seres humanos, dar-lhes certas ferramentas que permitam questionar, independentemente de onde possam estar trabalhando".

Boa leitura! 